\title{
Bond and Compressive Strength of Masonry for Locally Available Bricks
}

\author{
K. M. C. Konthesingha , C. Jayasinghe and S. M. A. Nanayakkara
}

\begin{abstract}
The bond between brick and mortar plays an important role in the ability of masonry to resist loads. The single and most important property of mortar is bond strength, and it is critical that this bond be complete, strong, and durable. The mechanism of bond between masonry units and mortars is known to be influenced by large number of factors. This paper presents an outcome of a study conducted on tensile and shear bond strength of masonry and compressive strength of masonry. It was also investigated to develop a possible relationship between shear and tensile bond strength. An experimental program was conducted to determine the impact of bond strength on compressive strength of masonry. Tensile bond strength was determi led by testing brick couplets and shear bond strength by testing triplets as recommended in relevant standards. Wall panels were tested to find out the compressive strength of masonry. The effect of different factors such as grading of sand, soaking time of bricks and type of bricks on the bond strength as well as the compressive strength of masonry was also found. The outcome of this research will have a higher benefit to the construction industry where masonry structures form a substantial portion.
\end{abstract}

Keyword: Masonry, Tensile bond strength, Shear bond strength, Compressive strength, Couplet, Triplet, Soaking time

\section{Introduction}

The resistance of masonry to tensile or shear loads depends on the bond between mortar and masonry units. The bond between brick and mortar plays an important role in the ability of masonry to resist loads. One of the most important properties of mortar is bond strength, and it is critical that this bond be complete, strong, and durable. The mechanism of bond between unit and mortar is not fully understood but is known to be influenced by large number of factors. Groot [1] lists a large number of parameters relating to the masonry unit characteristics, mortar characteristics, and bond morphology. The composition of mortar, binder/sand ratio, water cement ratio, porosity and pore size distribution of the brick and the moisture in the brick at the time of construction are some of the important parameters. It is known that the behaviour of masonry bond is extremely complex and most investigations done so far have been of a phenomenological nature, applying to specific combinations of materials.

Lowrence [2] attempted to understand the mechanism of bond development between mortar and brick. These studies showed that the brick-mortar bond is due to the network of cement hydration products deposited on the brick surface and inside the brick pores as well. Rao et al. [3] found that the higher values for flexural bond strength of masonry could be obtained by using composite mortars like cement-soil and cement-lime mortar when compared to pure cement mortar. The initial moisture in the brick has a role in the penetration of hydration products into the brick pores. An experiment done by Samarasinghe [4] found that partly wetted bricks showed greater bond strength than dry and saturated bricks.

Reo et al. [5] made a preliminary study of the influence of bond strength on compressive strength of masonry. The study showed that the masonry compressive strength is not reduced significantly even when the mortar strength is reduced significantly if the brick mortar bond strength is not altered.

K.M.C.Konthesingha, B. Sc. Eng. (Hons), Post graduate researcher Department of Civil Engineering, Universityof Moratuwa

Eng. (Dr.) (Mrs.) C.Jayasinghe,B. Sc. Eng. (Hons), (Moratuwa),M.Eng (Moratuwa), PhD (Moratuwa), CEng, MIE (SL), Senior lecturer, Department of Civil Engineering, University of Moratuwa.

Eng. (Dr.) S.M.A.Nanayakkara,B. Sc. Eng. (Hons), (Moratuwa), M.Eng. (Tokyo), D.Eng. (Tokyo), Senior lecturer, Department of Civil Engineering, University ofMoratuwa. 


\section{Objectives}

This research study has been aimed at following objectives:

- To determine tensile bond strength of masonry with different brick and sand types.

- To determine shear bond strength of masonry for comparison with tensile bond strength.

- To investigate the influence of sand and brick types on masonry bond strength and ultimate compressive strength.

\section{Methodology}

In order to achieve the above objectives, following methodology was adopted:

- Three sand types and three brick types were selected for the study to investigate the influence of different types of materials on masonry strength.

- Tensile bond strength was determined by testing brick couplets in accordance with ASTM C 952 -76 [6] with different brick, sand and cement types.

- Shear bond strength was determined by testing brick triplets and it was compared with tensile bond strength.

- Wall panels were constructed and tested as stated in BS 5628: part 1: 1992 [7] to determine the load at first crack and ultimate compressive strength of masonry.

\section{Bond Strength and Compressive Strength of Masonry}

This study has been focused at tensile and shear bond strengths and compressive strength of masonry.

\subsection{Tensile bond strength of mortar joints}

In order to determine the tensile bond strength, brick couplets were made in accordance with ASTM C 952 -76. Past research has shown that the moisture content of the units at the time of laying is of importance in determining the tensile bond strength. A study carried out by Sinha [8], on brick couplets at various moisture contents at the time of laying between oven dry and fully saturated has shown extreme variability of tensile bond strength. Although there is no clear relationship between moisture content and tensile bond strength, it will be noted that only very low values for bond strength were found as the bricks reached their saturation moisture content.

Anderson [9] have reported the results of the tests on crossed brick couplets for three types of brick, which again show that the moisture content at the time of laying influences the bond strength. However the effect depends on the type of bricks and on the sand grading. In general higher the fines content of the sand the lower the bond strength.

\subsection{Shear bond strength of mortar joints}

Shear bond strength was determined by testing brick triplets as recommended by Hendry [10]. Samarasinghe and Lawrence [4] examined the effect of high suction rate of low strength bricks of Sri Lanka on the brick mortar bond through a brick triplet shear test. They found that partly wetted bricks showed greater bond strength than dry and saturated bricks. In general shear bond strength increases as the compressive strength of mortar increases.

\subsection{Compressive strength of brick masonry}

Compressive strength is the main design parameter of $a$ masonry wall. The strength of masonry in compression, tension and shear has been the subject of systematic investigation over a very considerable period. Grenly [11] studied the effect of various mortars on flexural and compressive strength of masonry and on the tensile bond strength of cross brick couplets. His results showed that, in general, flexural and tensile bond strengths increase with the strength of mortar and the strength of brick. The masonry compressive strength also showed a similar trend.

This investigation attempts to find the variation of masonry strength with locally available bricks.

\section{Experimental Programme}

\subsection{Materials used}

\section{Burnt clay bricks}

In Sri Lanka, burnt clay bricks are typically manufactured by employing $a$ manual moulding process and then are burnt in kilns. 
Also there are standard bricks that can found in the market. Locally available hand moulded burnt clay bricks and standard clay bricks were used in this experiment, which are identify B1, B2 and B3 separately. The unit strength of B1 and B3 are $4.7 \mathrm{~N} / \mathrm{mm}^{2}$ and $6 \mathrm{~N} / \mathrm{mm}^{2}$ respectively whereas $\mathrm{B} 2$ is $12.1 \mathrm{~N} / \mathrm{mm}^{2}$, which shows that B2 is a much stronger brick.

\section{Sand}

Three different sand types were used for this experimental programme. This includes two ordinary sand varieties obtained from market (designated as S1 and S3) and offshore sand (designated as S2) for comparison purposes. The particle size distribution of the three sand types were obtained by conducting sieve analysis test on each type according to BS 812: 1985 [12]. The sieve analysis results for the above sand types are given below. (Fig. 01)

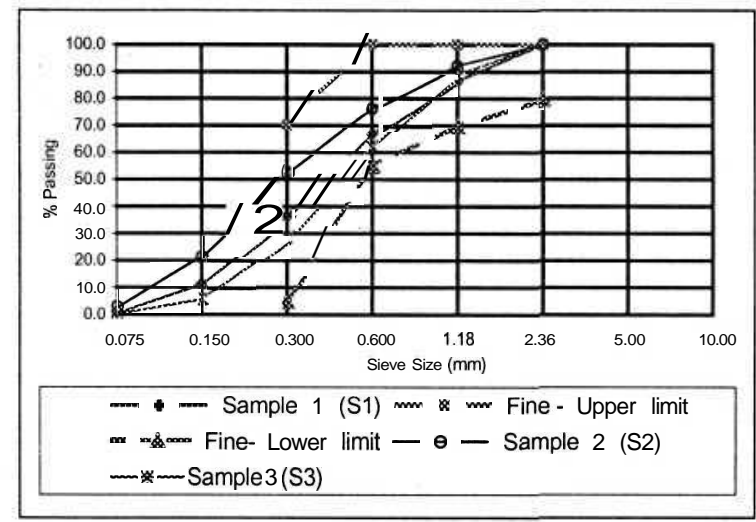

Figure 1: Grading curves for three different sand types S1,S2 and S3, which is within the Grading Zone F (Fine zone) of BS 882: 1992 [13].

\section{Cement}

The Ordinary Portland cement was used for this experimental programme.

\subsection{Testing carried out}

Brick-mortar bond strength can be experimentally studied by determining the tensile bond strength and shear bond strength.

The tensile bond strength was determined by couplet test according to ASTM C 952 -76 and the shear bond strength was determined by triplet test. Compressive strength of masonry was determined by testing wall panels according to BS 5628: part 1: 1992.
Sarangapani et al. [14] have done a research study to find out the tensile and shear bond strength of masonry by using modified test apparatus for testing.

\subsubsection{Tensile bond strength: Cross brick couplet test}

Cross couplets were made with different sand types using different brick types. The mortar bed joint thickness of $12 \mathrm{~mm}$ was maintained in all the cases by using the metal mould specified in the ASTM C 952-76 (Fig. 02). Figure 03 shows the prepared brick couplet specimen.

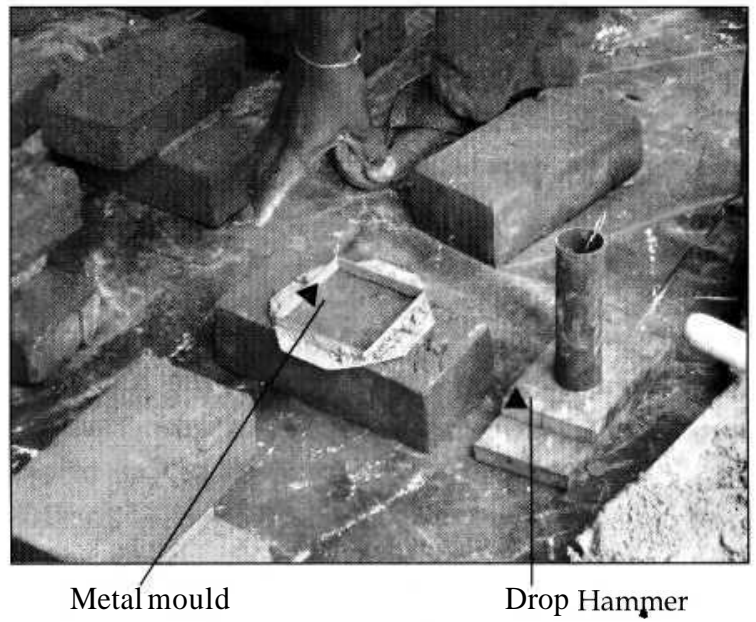

Figure 2: Apparatus usedfor making couplets

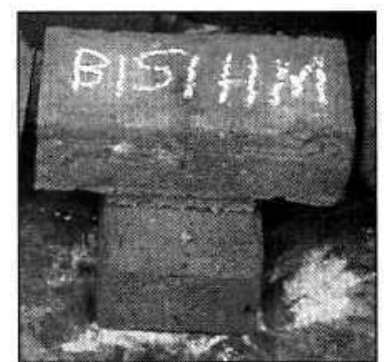

Figure 3: Brick couplet specimen

Loading was applied using a jack of five-ton capacity and proving ring arrangement as shown in Figure 04. The jack was operated manually and the load was applied to the couplet at a constant rate by continuously rotating the screw of the jack. The bond strength of the couplet was calculated based on the failure load and bond area between brick and mortar. 


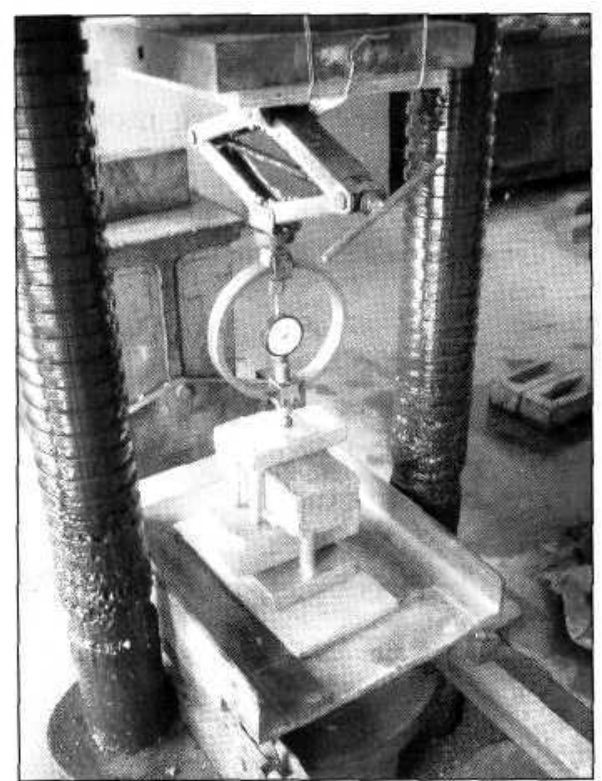

Figure 4: Apparatus usedfor testing couplets

Tensile bond strength varies with the soaking time of the brick. In order to find the optimum soaking time, a testing programme has been carried out with varying times of immersion of the brick in water. Commonly available bricks and commonly available sand were used for this test. The time of soaking was varied from 0 to 10 minutes prior to casting the couplets and for each time period of soaking, five samples were tested. The results are shown in Figure 05. The results indicated that the tensile bond strength is increasing with the brick soaking time up to six minutes and after that it decreases. Therefore the bricks were soaked for six minutes prior to use for the other tests.

Ten samples of couplets were made to study the dependency of tensile bond strength on each variable. Three different sand types and three different brick types were used for this test. A tested sample is shown in Figure 06.

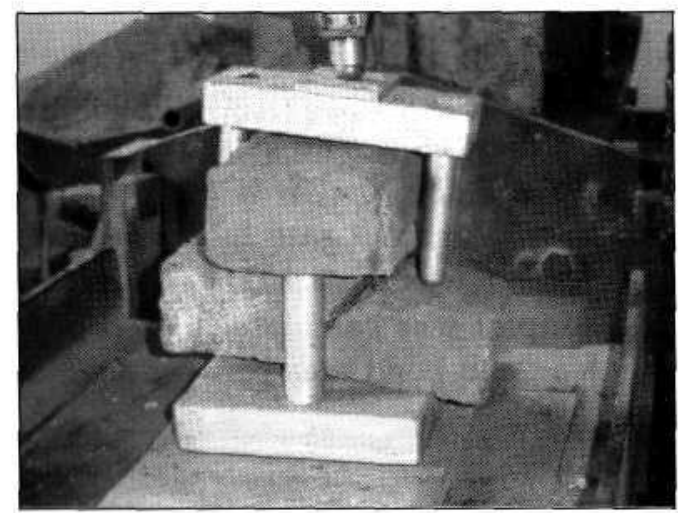

Figure 6: Tested brick couplet

\subsubsection{Shear bond strength: Triplet test}

Shear bond strength was determined by testing brick triplets as recommended by Hendry [10].

Five samples of triplets per variable were made. The test specimen of a triplet is shown in Figure 07. The brick was soaked forsix minutes before making the sample.

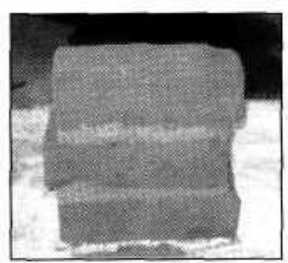

Figure 7: Brick triplet specimen

AMSLER testing machine was used to load the triplet as shown in Figure 08.

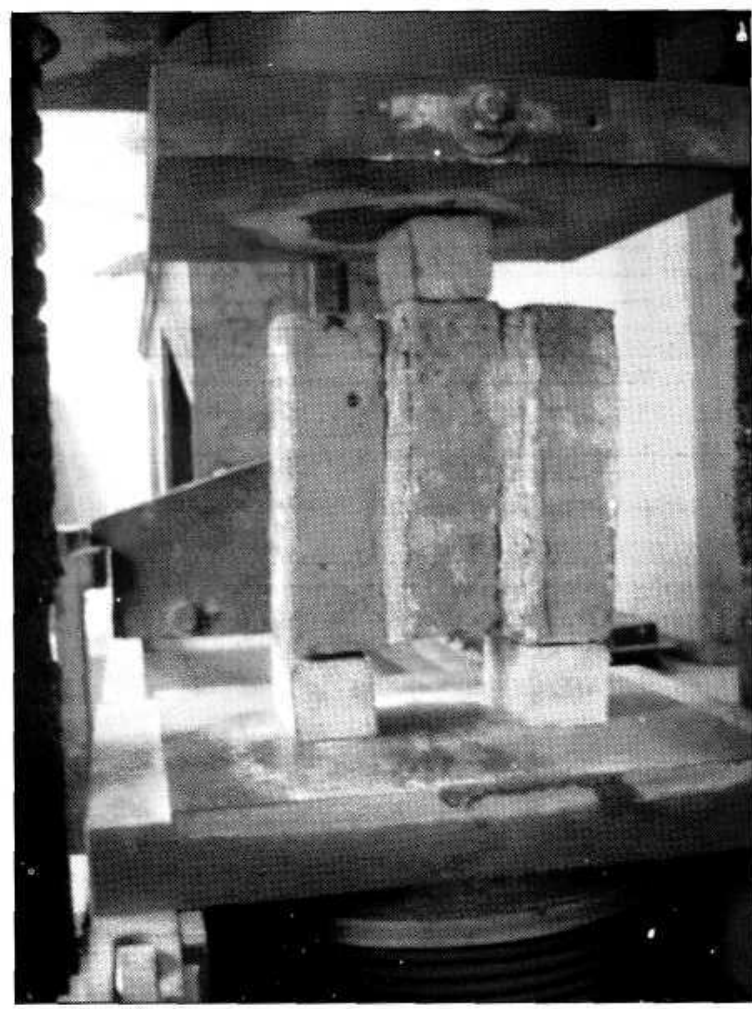

Figure 8: Testing triplet specimen

\subsubsection{Compressive strength of brick masonry}

Compressive strength is the main design parameter of a masonry wall. In order to determine the compressive strength of brick masonry with different brick types, a series of tests was conducted. Two identical wall panels were constructed to the dimensions specified in BS 5628: Part 1: 1992, and tested after 28 days of casting. 


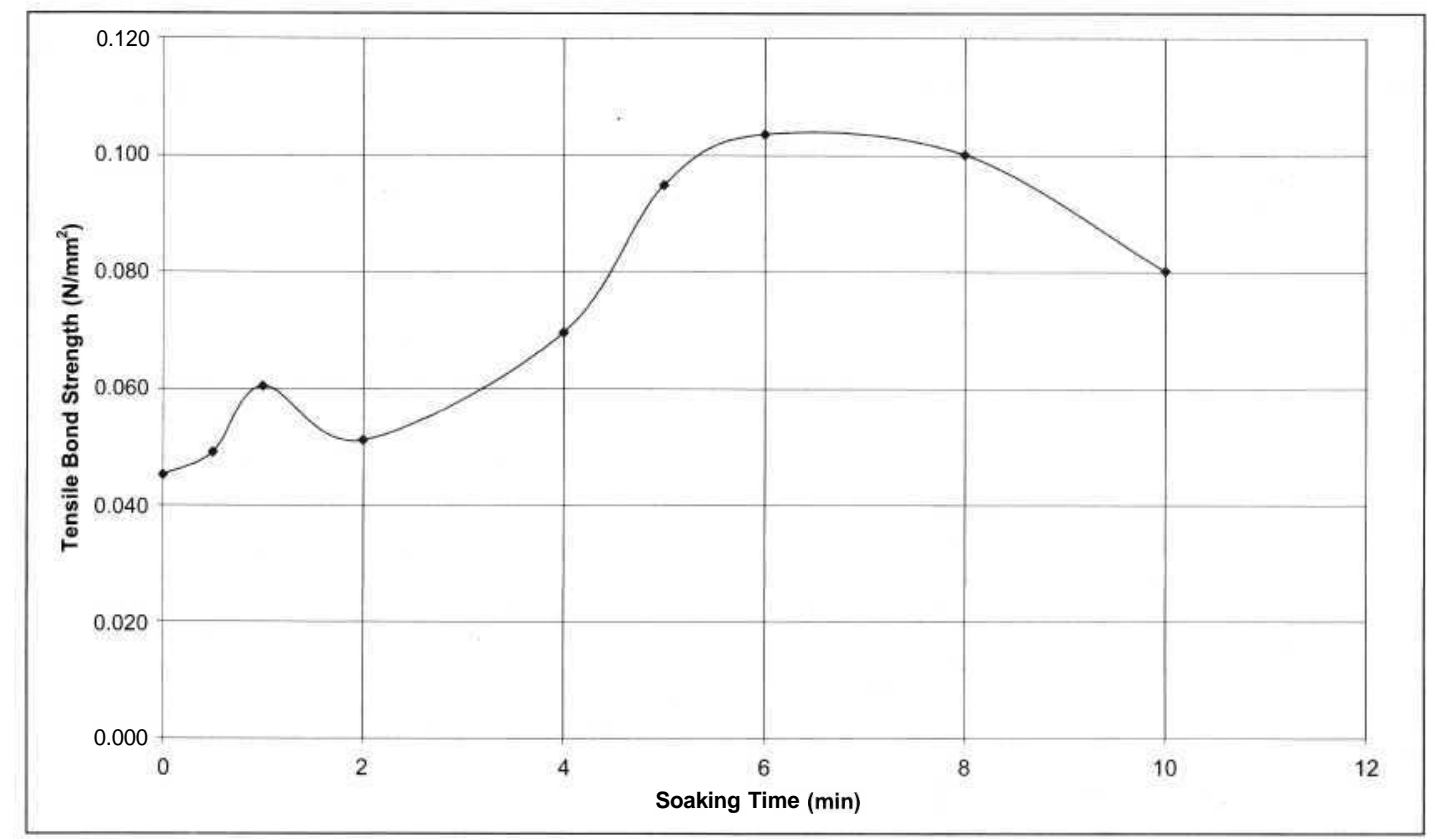

Figure 5: Variation of tensile bond strength with soaking time of bricks

All the panels were constructed with English bond pattern using Bl (normal-hand moulded) and B2 (Standard) bricks. The unit strength of $\mathrm{B} 1$ is $4.7 \mathrm{~N} / \mathrm{mm}^{2}$ whereas $\mathrm{B} 2$ is $12.1 \mathrm{~N} / \mathrm{mm}^{2}$, which shows that $\mathrm{B} 2$ is a much stronger brick. Bricks were immersed in water for about 6 minutes before laying in the wall. The mortar thickness was maintained at about $10 \mathrm{~mm}$ using the gauge rod. The panels were built on $50 \mathrm{~mm}$ thick timber planks to facilitate transportation to the testing machine. In order to maintain the same workmanship, all panels were constructed by the same mason.

Figure 09 shows a loading of a masonry brick panel according to the procedure specified in BS 5628: part 1: 1992.

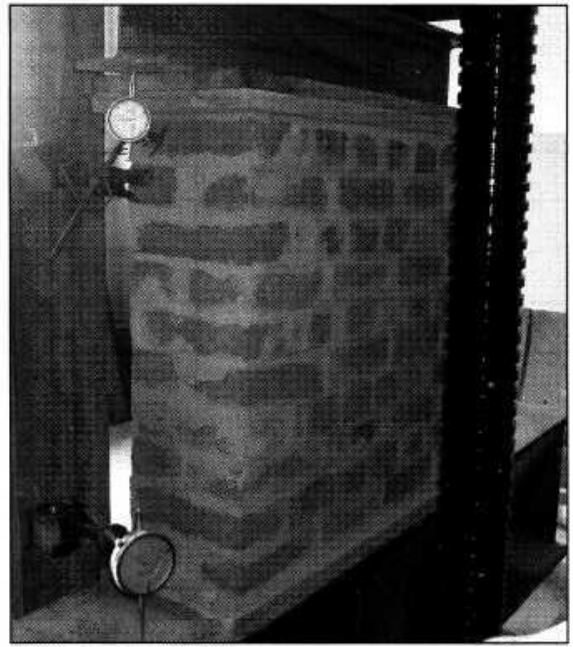

Figure 9: Loading of brick panel
Load at first crack, crack pattern and crushing load were recorded for each panel. A tested brick panel is shown in Figure 10.

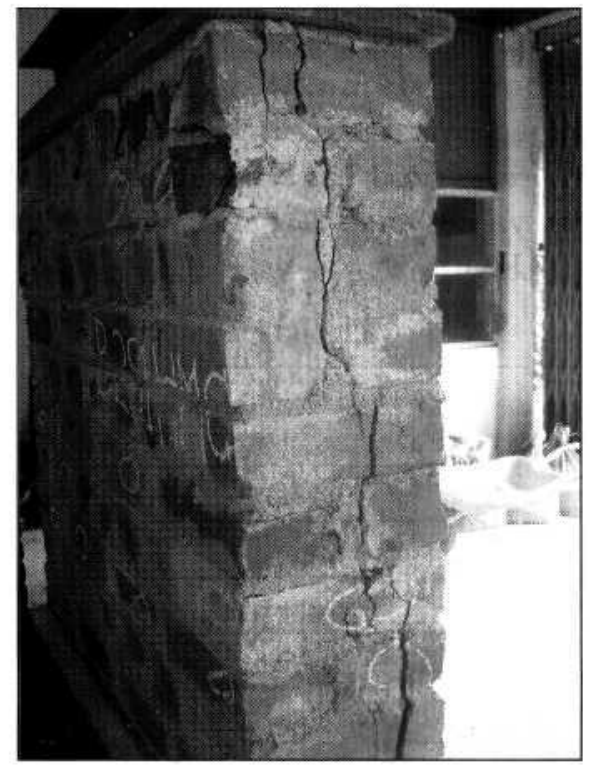

Figure 10: Tested brick panel

\section{Results and Analysis}

The tensile bond strength results have shown that the moisture content of the units at the time of laying has a substantial effect on the bond strength. This experimental study has shown that 6 minutes soaking of bricks can give the highest bond strength. Hence it is recommended to soak the bricks for about 6 minutes before laying in the wall. 
Although there is $a$ high scatter in results, relatively high tensile bond strength values were obtained with S2 sand. The results obtained from the couplet test are given in Fig.ll.

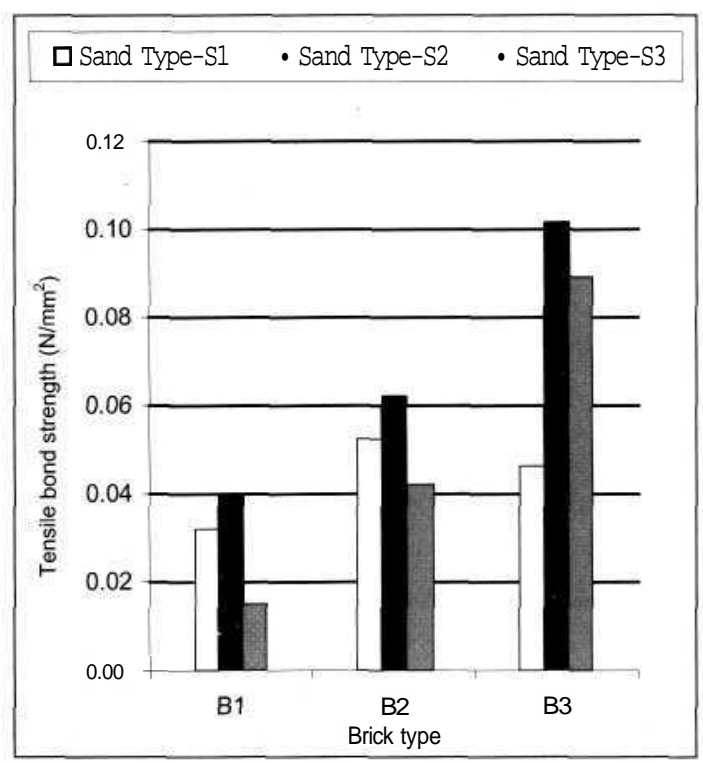

Figure 11: Tensile bond strengths of masonry

Shear bond strength of masonry was determined by testing brick triplets. For both brick types S1 sand has shown low shear bond strength values than $\mathrm{S} 2$ sand. The results are shown in Figure 12.

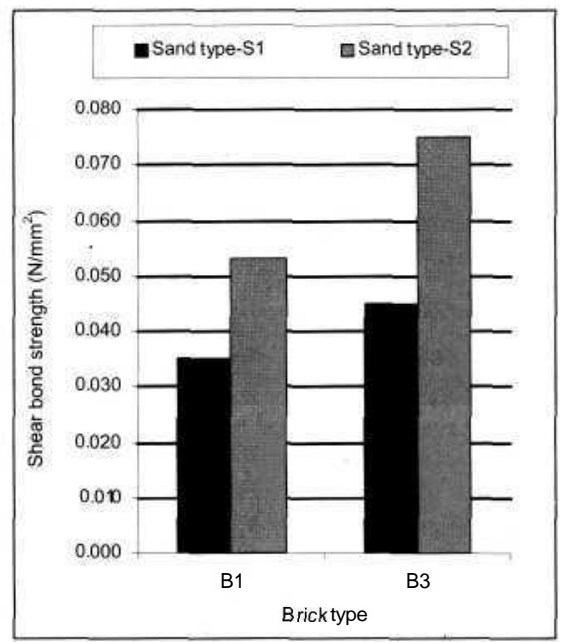

Figure 12: Shear bond strengths of masonry

The comparison between shear bond strength and tensile bond strength is given in Figure 13(a) and 13(b)

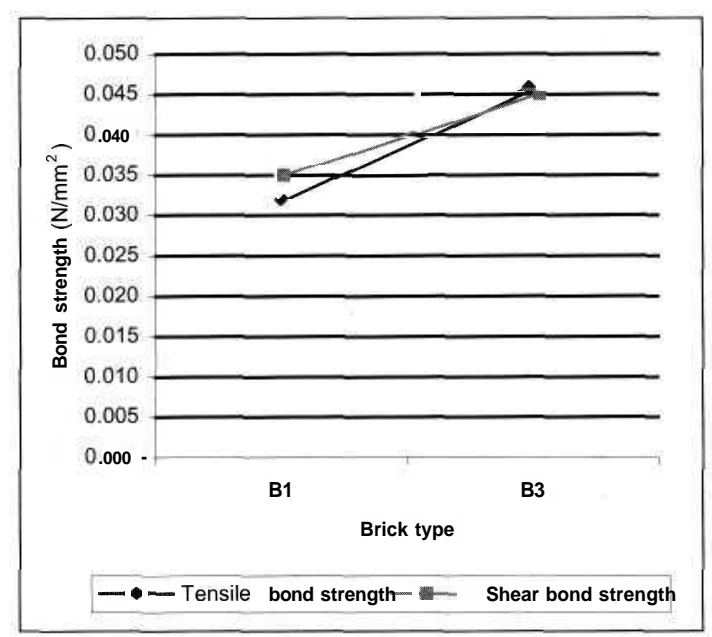

Figure 13 (a): Shear and tensile bond strengths for sand type 1 (S1)

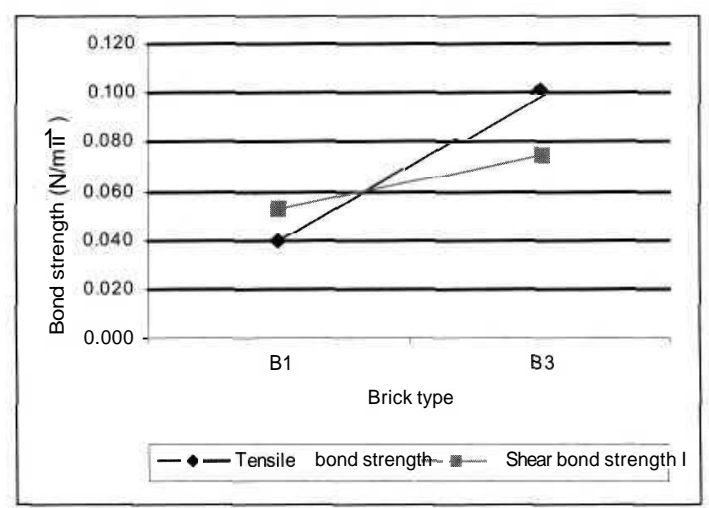

Figure 13 (b): Shear and tensile bond strengthsfor sand type 2 (S2)

The compressive strength of walls and load deformation characteristics were determined and the modulus of elasticity (E value) was determined. Stress- strain curve used to evaluate the $\mathrm{E}$ value for one determined brick type is given in Figure 14.

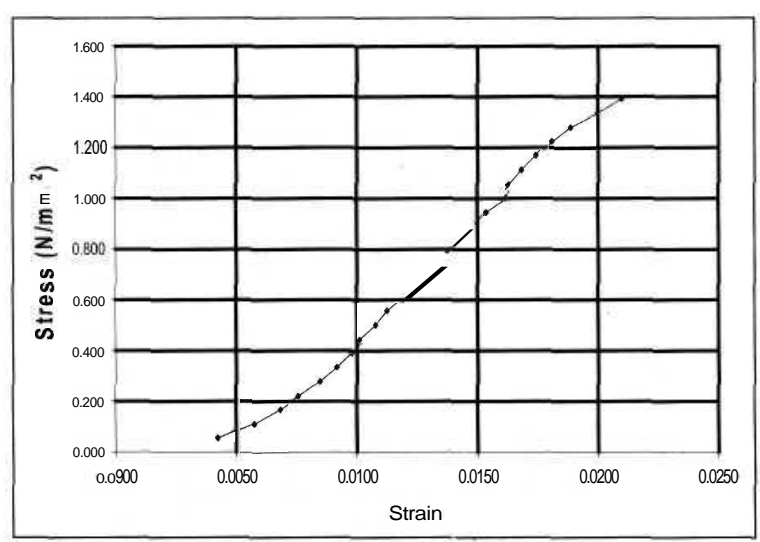

Figure 14: Stress- strain curvefor brick type B1

The comparison of compressive strength values and modulus of elasticity is given below (Table 1). It clearly indicates that $B 2$ or standard bricks 
give higher $\mathrm{E}$ values and higher compressive strength.

It should be noted that Grade 25 concrete has an $\mathrm{E}$ value of $25 \mathrm{kN} / \mathrm{mm}^{2}$. This indicates that the $\mathrm{E}$ value of local brickwork is very low when compared with concrete.

Table 1 - Compressive strength and $E$ values

\begin{tabular}{|c|c|c|}
\hline $\begin{array}{l}\text { Brick } \\
\text { Type }\end{array}$ & $\begin{array}{c}\text { Compressive Strength } \\
\left(\mathrm{N} / \mathrm{mm}^{2}\right)\end{array}$ & $\begin{array}{c}\text { E value } \\
\left(\mathrm{kN} / \mathrm{mm}^{2}\right)\end{array}$ \\
\hline B1 & 1.358 & 0.097 \\
\hline B2 & 2.642 & 0.226 \\
\hline
\end{tabular}

Higher wall strengths were obtained with standard bricks hence for load bearing constructions, standard bricks are recommended.

\section{Conclusions}

The grading curves of three sand types used in the study are almost within the BS limits for the fine aggregate specified in BS 812: 1985 [12]. However, $\mathrm{S} 2$ sand is relatively fine and the average tensile bond strength with $\mathrm{S} 2$ has always shown higher values.

Soaking time of bricks has a significant effect on bond strength and it is recommended to use 6 minute soaking time before laying the bricks.

Comparison of tensile and shear bond strength shows that the bricks and mortar with higher tensile bond strength gives a higher shear bond strength. Also the tensile and shear bond strength depends on brick type.

The $\mathrm{E}$ value of brick type $\mathrm{Bl}$ is $0.097 \mathrm{kN} / \mathrm{mm}^{2}$ and the same for brick type $\mathrm{B} 2$ is $0.226 \mathrm{kN} / \mathrm{mm}^{2}$. Although the above $\mathrm{E}$ values are less than the $\mathrm{E}$ value for the standard bricks, the good quality B2 bricks has a considerably high E value. Higher wall strengths were observed with standards bricks and therefore standard bricks can be used for load bearing construction.

\section{Acknowledgement}

The authors wish to express their sincere thanks to Holcim (Lanka) Limited for providing funds to complete this research successfully. The support given by Mr. Kapuruge, Mr. Madanayaka and Mr. Gunasekara, the technical officers of Department of Civil Engineering by providing necessary equipment and guidance for the success of the testing series is also appreciated.

\section{References}

1. Groot, C., 1993, "Effects of water on mortar-brick bond", PhD thesis, Faculty of Civil Engineering, Delft Univ. of Technology, the Netherlands.

2. Lawrence, S., and Cao, H.T, 1987, An Experimental Study of the Interface between Brick and Mortar', Proceeding of the North American Masonry Conference (Los Angeles), pp. 48 1-14.

3. Venu Madhawa Rao, K., Venkatarama Reddy, B.V., and Jagadsh, K.S, 1996, "Flexural bond strength of masonry using various blocks and mortars", Mater. Civ. Eng., 11(3), 249-256.

4. Samarasinghe, W., and Lawrence, S. J., 1992. "Effect of high suction rate in low strength bricks on brick mortar bond." Proc., 4th Int. Seminar on Structural Masonry for Developing Countries, Madras, India, 43-50.

5. Venumadhava Rao, K., Venkatarama Reddy, B.V., and Jagadish, K.S., 1995, "Influence of flexural bong strength on the compressive strength of masonry" Proc., National conf. on Civil Engineering Materials and Structures, Osmania Univ., Hyderabad, India, 103-108.

6. ASTM C952-76, Standard Test Method for Bond Strength of Mortar to Masonry Units, American Society for Testing and Materials, Philadelphia, 742-753.

7. BS 5628:Part 1; 1992, Code of Practice for Use of Masonry, Part 1.Structural use of unreinforced masonry, British Standard Institution, United Kingdom.

8. Sinha, B.P., 1967, "Model studies related to load bearing brick work", PhD thesis, Univ. of Edinburgh, U.K.

9. Anderson C. and Held, L.C., 1986, The effect of sand grading on mortar properties and the tensile bond of brickwork specimens, Proc. British Masonry Society, 1, pp1-6.

10. Hendry, A.W., 1990, Structural Masonry, MACMILLANEDUCATION LTD, United Kingdom.

11. Grenly, D.C., 1993, "Study of the effect of certain modified mortars on compressive and flexural strength of masonry." Designing, engineering, and constructing with masonry products, F.B.Johnson, ed., Gulf, Houston, 28-33.

12. BS 812, 1985, Testing aggregate, Part 103: Methods for determination of particle size distribution, Section 103.1: Sieve tests, British Standard Institution, United Kingdom.

13. BS 882, 1992, Specification for aggregates from natural sources for concrete, British Standard Institution, United Kingdom.

14. Sarangapani, G., Venkatarama Reddy, B.V., and Jagadsh, K.S, 2005, Brick- Mortar Bond and Masonry Compressive Strength, JOURNAL OF MATERIALS IN CIVIL ENGINEERING, PP 229-237. 